\title{
Biosynthesis of copper nanoparticles using aqueous extract of Capparis spinosa fruit and investigation of its antibacterial activity
}

\author{
Katrin EBRAHIMI, Sima SHIRAVAND, Hossein MAHMOUDVAND
}

\begin{abstract}
The present study was aimed to use the aqueous extract of Capparis spinosa to synthesize the copper nanoparticles and also evaluated their antibacterial activities again some pathogenic bacterial strains. UV-vis spectroscopy analyses, fourier transform of infrared (FTIR), scanning electron microscopy (SEM), and energy dispersive X-ray (EDX) were used to identify the synthesized nanoparticles. The antimicrobial activity of the synthesized copper nanoparticles was investigated using disk diffusion method and broth microdilution against some Gram-positive and Gram-negative bacteria. After adding the extract to the copper sulfate solution, the color of the solution changed from light blue to yellowish green. Existence of a maximum peak at the wavelength of $414 \mathrm{~nm}$ confirmed the
\end{abstract}

Katrin Ebrahimi

Department of Biology, Payame Noor University, Tehran, Iran

Sima Shiravand

Department of Biochemistry, Lorestan Uniersity, Khorramabad, Iran

Hossein Mahmoudvand

Razi Herbal Medicine Research Center, Lorestan University of Medical

Sciences, Khorramabad, Iran

Corresponding Author:

Hossein Mahmoudvand

e-mail:dmahmodvand@gmail.com

Submitted / Gönderilme: 26.06.2017 Revised / Düzeltme: 29.07.2017

Accepted / Kabul: $\quad 02.08 .2017$

How to cite this article: Ebrahimi $\mathrm{K}$, Shiravand M, Mahmoudvand $\mathrm{H}$. Biosynthesis of copper nanoparticles using aqueous extract of Capparis spinosa fruit and investigation of its antibacterial activity. Marmara Pharm J. 2017; 21 (4): 866-871 formation of the copper nanoparticles. FTIR spectrum analysis showed that the factor groups created a coating extract on the surface of the nanoparticles. Scanning electron microscopy demonstrated the particle size between 17 and $41 \mathrm{~nm}$. These findings showed that Staphylococcus aureus and Bacillus cereus as Gram-positive bacteria were most susceptible to synthesized copper nanoparticles in comparison with the Gram-negative bacteria (Klebsiella pneumoniae, and Escherichia coli). The obtained findings demonstrated that the aqueous extract of $C$. spinosa acts as a reviver and stabilizer factor. The synthesized copper nanoparticles demonstrated activity against both Grampositive and Gram-negative bacteria.

Keywords: Nanoparticles; antimicrobial; green synthesis;copper

\section{Introduction}

Nanotechnology plays an important role in the modern research [1]. This technology can be applicable in a wide range of fields such as all pharmacology, food and nutrition, chemical industries, energy sciences, cosmetics; further, it can be used for the treatment of infections, cancer, allergies, diabetes, and inflammation [1-5]. Green chemistry refers to the design and development of chemical products and processes in order to minimize the dangerous uses of the environment [6]. Nanoparticles are synthesized through chemical and physical methods. Compared to these methods, green synthesis has been one of the best methods for producing nanoparticles in recent years. Green synthesis has numerous advantages, compared to other methods, including cost-effectiveness, simplicity, use of lower temperatures, use of non-toxic materials, as well as compatibility with applied medical and nutritional programs [7]. Green synthesis method is being developed and is an environmentally-friendly method as well [7-8]. In this method, the extract is used as a reducing agent and coating for nanoparticles. Owing to their electrical, optical, and catalytic properties, copper nanoparticles are widely used and have 
various medical, antifungal, and antibacterial applications [9, 10]. Copper nanoparticles are toxic for many microorganisms such as Escherichia coli, Staphylococcus aureus, and Pseudomonas aeruginosa bacteria and, in the meantime, are non-toxic for animal cells [11]. Several different plants have been used for the synthesis of nanoparticles using green synthesis method [12]. Nanoparticles are synthesized using all parts of the plantincluding stem, flower, fruit, leaves, and bark [13]. Capparidaceae is a large family of the flowering, angiospermous, dicotyledonous, and dialypetalous plants and Capparis is the largest genus in this family [14]. The scientific name of Capparis spinosa is known as Koor, Kabar, Kooraz, Koorgiah, Khiarshang, Alafmar, Lijin, and Daghgarpooziin Iran; further, it is called Batlisk in Lorestan Province, western İran [14]. This plant is a shrub with stalks lying on the ground, simple leaves with thorn-like stipules, large and fragrant white or purple flowers, and unequal convex sepals with 8 to 15 stamens [15]. In the present study, the fruits of this plant were used for the synthesis of copper nanoparticles and investigation of their antibacterial effects.

\section{Results}

After adding the extract to the copper sulfate solution, the color of the copper sulfate changed from light blue to yellowish green, which was due to the synthesis of the copper nanoparticles.

\subsection{UV-Vis spectrum analysis}

The nanoparticles synthesized in the zone of $414 \mathrm{~nm}$ had a peak maximum. The results show that the characteristic of the resonance band of the surface plasmon at the wavelength of $414 \mathrm{~nm}$ occurred for the copper nanoparticles.

\subsection{FTIR spectrum analysis}

Results of FTIR showed that the biomolecules in the extract reduced the copper sulfate solution; further, they would be used as coatings for nanoparticles. The bands at 3380, 2928, 1741, 1604, 1400, 1050, and 1271 were related to the $\mathrm{O}-\mathrm{H}$ stretching of alcohol and phenol, $\mathrm{C}-\mathrm{H}$ stretching of aliphatic group, $\mathrm{C}=\mathrm{O}$ stretching of ester carbonyl, $\mathrm{C}=\mathrm{C}$ stretching of the aromatic ring, and $\mathrm{C}-\mathrm{O}$ stretching of ester, respectively.

The bands showed that the extract of C. spinosa was rich in polyphenols, sterols, and sorptive fatty acids in the zones of 3398, 2924, and 1739, respectively. Since the copper nanoparticles had bands at 1624, 1359, and 1072, it could be concluded that the biomolecules of the extract acted as both reducer and coating for copper nanoparticles; thus, they can protect the copper nanoparticles against oxidation and being transformed into copper oxide.

\subsection{Scanning electron microscope (SEM)}

After confirming the synthesis of nanoparticles using color change and Vis-UV and FTIR sorption spectra, the morphology of the synthesized nanoparticles was investigated by the scanning electron microscope at University of Lorestan, Khorramabad, Iran. Based on the obtained images, the synthesized copper nanoparticles had spherical morphology and the size of the particles was determined between 17 and $41 \mathrm{~nm}$ (Figure 1).
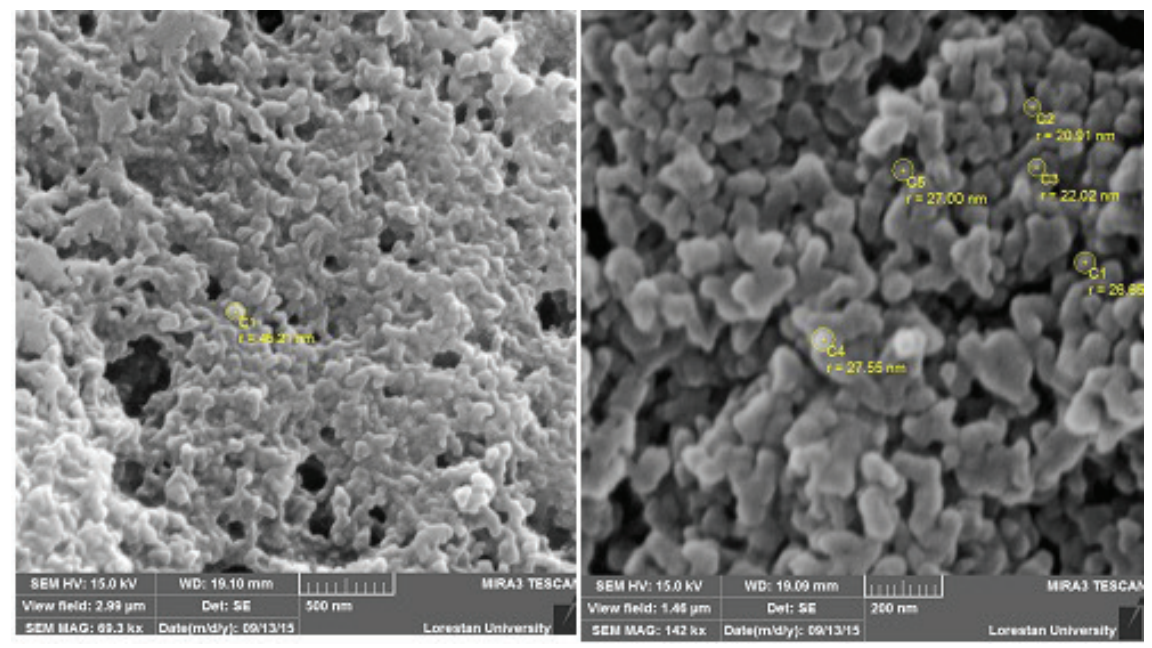

Figure 1. Scanning electron microscope of copper nanoparticles synthesized using aqueous extract of Capparis spinosa fruit 


\subsection{Investigating EDX spectrum}

The presence of metallic copper was confirmed by EDX analysis. The copper nanoparticles had a sorptive peak at $1 \mathrm{Kev}$, which is an index for metallic nanoparticles of copper. Oxygen was the main contamination in this spectrum. Oxygen was resulted from physical absorption during sample preparation.

\subsection{Antibacterial activity of synthesized nanoparticles}

Table 1 shows the antibacterial effects of synthesized copper nanoparticles against some pathogenic bacterial strains. Copper nanoparticles demonstrated remarkable antibacterial activity against Gram-positive bacteria (S. aureus and B. cereus) and Gram-negative bacteria (K. pneumoniae and E. coli). These findings showed that $S$. aureus and B. cereus as Grampositive bacteria were most susceptible to synthesized copper nanoparticles in comparison with the Gram-negative bacteria.

Table 1. Minimum inhibitory concentration (MIC) and minimum bactericidal concentration $(\mathrm{MBC})$ values copper nanoparticles against some pathogenic bacterial strains.

\begin{tabular}{ccc}
\hline Bacterial strain & $\mathrm{MBC}(\mathrm{mg} / \mathrm{ml})$ & $\mathrm{MIC}(\mathrm{mg} / \mathrm{ml})$ \\
\hline Bacillus cereus & 5 & 5 \\
Staphylococcus aureus & 5 & 5 \\
Escherichia coli & 10 & 10 \\
Klebsiella pneumoniae & 10 & 10 \\
\hline
\end{tabular}

\section{Discussion}

Investigating the results showed that the use of the aqueous extract of C. spinosa is a simple, quick, inexpensive, environmentally-friendly, and applicable method which can be performed in any kind of laboratory for the synthesis of copper nanoparticles. In this method, the chemical and toxic reagents are not used and no pollution is created for the environment; therefore, it is superior to other physical and chemical methods of nanoparticle synthesis. Nanoparticles produced by this method are very stable and renewable. Copper nanoparticles have various applications in medicine, including anti-cancer, anti-parasitic, antifungal, and antibacterial activities, food packaging, and wound dressings; moreover, these nanoparticles have various industrial applications including $\mathrm{m}$ electrical capacitors, heat transfer, super-strong materials, sensors, catalysts, etc [2]. Results showed that the nanoparticles synthesized by this method were nearly spherical with the size ranging from 41 to $17 \mathrm{~nm}$; further, the synthesized copper nanoparticles had the capability of fighting the pathogenic microorganisms. The observed growth inhibition halo against the Grampositive bacteria was more than the halo against the Gramnegative ones. So far, different plants have been used for the synthesis of copper nanoparticles, including Ocimus sanctum by Kulkarni (2014), Capparise zeylanica by Saranya Adevi et al. (2014), Gloriosa superbal by Naika et al. (2015), extract of Vitis vinifera by Subbaiya Angrasan (2014), Nerium oleander by Gopinath et al. (2014), and Artabotrys odoratissimus by Kathad and Gajera (2014) [16-21].

EDX images proved the existence of copper nanoparticles and, using SEM, their size was determined to be less than $50 \mathrm{~nm}$. Saranya Adevia et al [17]. expressed the size of the synthesized particles between 100 and $50 \mathrm{~nm}$.

Subhankari et al. reported the particle size of $25-40 \mathrm{~nm}$ [22]. Kulkarni reported the particle size of $77 \mathrm{~nm}$, while Shend et al. reported the particle size of $60-10 \mathrm{~nm}$ [23]. Investigating the antibacterial activity of the nanoparticles against Gram-positive and Gram-negative bacteria showed that the effect of these particles on the Gram-positive bacteria was greater than the one on the Gram-negative bacteria. Results of this study were consistent with the results presented by Angrasan and Subbaiya.

\section{Conclusion}

Results showed that the aqueous extract of $C$. spinosa acts as a reviver and stabilizer factor. The synthesized copper nanoparticles demonstrated activity against both Grampositive and Gram-negative bacteria.

\section{Materials and methods}

\subsection{Plant material}

The Capparis spinosa fruits were collected from rural regions of Kouhdasht, Lorestan Province, in July 2016 by Mr. Mohammad Mehrnia, and identified by Ms. Katrin Ebrahimi. A voucher specimen was deposited in the Herbarium of Agricultural Research Center, Khorramabad, Iran (No. 13840).

Fruits of C. spinosa were collected from city of Kouhdasht, Lorestan Province. After being identified, the collected specimens were washed with distilled water and dried in the shade away from the direct sunlight; then, they were milled to powder. Afterwards, the powder of the plant was stored in the refrigerator for later uses. 


\subsection{Preparation of aqueous extract}

First, $10 \mathrm{~g}$ of the C. spinosa powder was poured in a flask and $200 \mathrm{ml}$ of deionized water was added to it; then, it was heated for $30 \mathrm{~min}$ at $70^{\circ} \mathrm{C}$. After reaching the room temperature, it was first filtrated with a filter paper and, then, the extract was centrifuged for $20 \mathrm{~min}$ at the speed of $12000 \mathrm{rpm}$. Next, the extract was stored in the refrigerator at $4^{\circ} \mathrm{C}[24,25]$.

\subsection{Synthesis of copper nanoparticles}

First, $75 \mathrm{ml}$ of the freshly prepared extract was added to 100 $\mathrm{ml}$ of the freshly prepared $0.01 \mathrm{M}$ copper sulfate solution while being constantly stirred on the stirred and then it was stored at $60^{\circ} \mathrm{C}$ for $24 \mathrm{~h}$ [26]; afterwards, it was centrifuged for $20 \mathrm{~min}$ at the speed of $12,000 \mathrm{rpm}$. This procedure was repeated twice in order to remove all the impurities. The color change of the solution from green to amber yellow indicated the formation of the nanoparticles. The synthesized nanoparticles were dried in the oven at $60^{\circ} \mathrm{C}$ for the following analyses [27, 28].

\subsection{Detection of nanoparticles}

\subsubsection{UV-Vis spectroscopy analysis}

Reduction of the copper ions to copper nanoparticles is the confirmation of surface plasmon resonance (SPR) of the copper nanoparticles. Thus, $300 \mu \mathrm{l}$ of the sample was diluted with $3 \mathrm{ml}$ of distilled water, and UV-Vis spectrum analysis was performed using a spectrophotometer device (JENWAY $6405)$ in the range of $300-700 \mathrm{~nm}[29,30]$.

\subsubsection{Fourier transform infrared spectroscopy}

FTIR spectrum analysis for C. spinosa extract and copper nanoparticles synthesized using the extract indicated the presence of the biological agents in the extract and led to the reduction of $\mathrm{Cu}^{2}$ to copper nanoparticles. The specimen and $\mathrm{KBr}$ granules were powdered together with the ratio of 1 to 100 (1/100 ratio) and then compressed into tablets; subsequently, the analysis was performed and measured using FTIR spectrophotometer (model Nicolet32) in the range of 400-4000 and with the resolution of $1-4 \mathrm{~cm} \mathrm{[31].}$

\subsubsection{Scanning electron microscope (SEM)}

Size and morphology of the synthesized nanoparticles were examined using electron microscopy (Mira3, Made in Czech) with $15 \mathrm{kv}$, magnification of x10, and resolution of $1 \mathrm{~nm}$.

\subsubsection{Energy dispersive $X$-ray (EDX)}

Energy dispersive X-ray spectroscopy along with SEM was used to investigate the presence of copper in SEM images.

\subsection{Preparation of culture medium and bacterium}

The solid culture and liquid culture media are used for the disk diffusion and MIC methods, respectively; therefore, in the present study, the Mueller Hinton agar and the Mueller Hinton Broth media were used as the solid and liquid culture media, respectively. To prepare the culture medium according to the written instruction, on the culture medium plate, a specified amount of the culture medium was dissolved in a specified volume of distilled water in an erlenmeyer flask. Then, it was placed in an autoclave to sterilize the culture medium. After the autoclave process, the liquid culture medium was put in the refrigerator. After reaching the temperature of $50^{\circ} \mathrm{C}$, the culture medium was poured in multiple plates under the hood; afterwards, when the culture medium turned into the solid form, the plates were inverted upside down and then stored in the refrigerator. During the test, the newly passaged bacteria should be used; for this purpose, a fresh culture was prepared from each bacterium just one day before the test, which was done with a loop on the Mueller Hinton agar culture medium. Plates were put in the incubator for $24 \mathrm{~h}$.

\subsection{Disk diffusion measurement}

The disk diffusion method was used to investigate the antibacterial activity of the nanoparticles against $S$. aureus (PTCC 1112), B. cereus (PTCC 1556), E. coli (PTCC 1330), and K. pneumoniae (PTCC 1053) [32]. Under sterile conditions, a loop of the $24 \mathrm{~h}$ culture of each bacterium was poured in the normal saline solution to yield the same opacity as $0.5 \mathrm{McF}$ arland standard $\left(1.5 \times 10^{6} \mathrm{CFU} / \mathrm{ml}\right)$; then, a homogeneous culture was prepared by a swap on the surface of the plate containing the Mueller Hinton agar culture medium. Next, $100 \mu \mathrm{l}$ of the specimen was poured on a blank disc, and the blank disc was fixed on the surface of the plate. Normal saline and amikacin were used as the negative and positive controls, respectively. After $24 \mathrm{~h}$ of storage at $37^{\circ} \mathrm{C}$ in the incubator, the diameter of the inhibition halo was measured.

\subsection{Determination of MIC}

MIC was determined in a sterile 96-well microplate using broth microdilution method [33]. For this purpose, first, 100 
$\mu \mathrm{l}$ of the Mueller Hinton broth culture medium (MHB) was poured in 10 wells of the microplate and $100 \mu$ lof the specimen was added to the first well of each row and thoroughly mixed with the sampler by turning up and down multiple times. Afterwards, $100 \mu$ l of the content of the first well was taken out and then added to the next well. This procedure was repeated until the $10^{\text {th }}$ well. Subsequently, $100 \mu \mathrm{l}$ was poured out from the $10^{\text {th }}$ well so that the concentration of the extract in each well became half of the previous well. From the $24 \mathrm{~h}$ the bacterium culture, a homogeneous suspension equivalent to the $0.5 \mathrm{McF}$ arland standard solution was prepared in the broth liquid culture medium and diluted 100 times; then, 100 $\mu \mathrm{l}$ was added to each well. After $24 \mathrm{~h}$ of incubation at $37^{\circ} \mathrm{C}$, the existence of opacity indicating the growth or non-growth of the bacterium was recorded; then, based on the definition, the most diluted well with no opacity was considered as MIC. The bacterial suspension and culture medium, the MHB, and the amikacin were used as the positive control, negative control, and standard antibiotic, respectively.

\subsection{Statistical analyses}

We used SPSS software, ver. 17, (SPSS Inc., Chicago). Data entry and statistical analysis and differences between the groups were determined using one-way analysis of variance (ANOVA) test. $\mathrm{P}$ value of less than 0.05 was considered statistically significant.

\section{Acknowledgements}

The authors would like to appreciate Payame Noor University, Khorramabad Branch, for sponsoring the project.

\section{Declaration of Interest}

The authors declare that there is no conflict of interest in this study.

\section{References}

1. Furno F, Morley KS, Wong B, Sharp BL, Arnold PL, Howdle SM, Bayston R, Brown PD, Winship PD, Reid HJ. Silver nanoparticles and polymeric medical devices: A new approach to prevention of infection. J Antimicrob Chemother 2004; 54 : 1019-24.

2. Brigger I, Dubernet C, Couvreur P. Nanoparticles in cancer therapy and diagnosis. Adv Drug Deliv Rev 2012; 64: 24-36.

3. Roy K, Mao HQ, Huang SK, Leong KW. Oral gene delivery with chitosan-DNA nanoparticles generates immunologic protection in a murine model of peanut allergy. Nat Med 1999; 5: 387-91.

4. Basarkar A, Singh J. Poly (lactide-co-glycolide)polymethacrylate nanoparticles for intramuscular delivery of plasmid encoding interleukin-10 to prevent autoimmune diabetes in mice. Pharm Res 2009; 26: 72-81.

5. Wilson DS, Dalmasso G, Wang L, Sitaraman SV, Merlin D, Murthy N. Orally delivered thioketal nanoparticles loaded with TNF- $\alpha$-siRNA target inflammation and inhibit gene expression in the intestines. Nat Mater 2010; 9: 923-8.

6. Mano Priya M, Karunai Selvia B, John Paul JA. Green synthesis of silver nanoparticles from the leaf extracts of Euphorbia hirta and Nerium indicum. Digest J Nanomat Biostruct 2011; 6: 869 -77 .

7. Chandrakant K, Tagad, Sreekantha Reddy D, Rohini A, Sungha P, Atul K, Sushma S. Green synthesis of silver nanoparticles and their application for the development of optical fiber based hydrogen peroxide sensor. Sens Actuators B Chem 2013; 183: 144- 9.

8. Yamini Sudha Lakshmi G, Fouzia B, Ezhilarasan, Arumugam, Sahadevan. Green synthesis of silver nanoparticles from Cleome viscosa: Synthesis and antimicrobial activity. International Conference on Bioscience, Biochemistry and Bioinformatics 2011; 5: 334-337.

9. Awwad AM, Salem NM. Green synthesis of silver nanoparticles by mulberry leaves extract. J Nanosci Nanotechnol 2012; 2: 125-8.

10. Jagtap UB, Bapat WA. Green synthesis of silver nanoparticles using Artocarpus heterophyllus Lam. seed extract and its antibacterial activity. Ind Crop Prod 2013; 46: 132-7.

11. Kalimuthu K, Babu RS, Venkataraman D, Bilal M, Gurunathan S. Biosynthesis of silver nanocrystals by Bacillus licheniformis. Colloids Surf B 2008; 65: 150-3.

12. Safarpour S, Givianrad MH, Beheshti P. Detection and determination of antioxidant compound of seed oil of Capparis spinosa L. in Iran. Iran J Med Aromat Plants 2012; 28: 153-60.

13. Mallikarjunaa K, Narasimhab G, Dillipa GR, Praveenb B, Shreedharc B, Sree Lakshmic C, Reddy BVS, Deva Prasad Raju B. Green synthesis of silver nanoparticles using Ocimum leaf extract and their characterization. Digest J Nanomat Biostruct 2011; 6: 181-6.

14. Zargari A, Medicinal Plants, Vol.2, Tehran University Publication, Tehran, Iran 1989, pp. 550.

15. Ghahraman A. Chromophytes of Iran, Vol.1 Tehran University Press, Tehran, Iran 1998, pp. 202.

16. Kulkarni VD, Kulkarni, PS. Green synthesis of copper nanoparticles using Ocimum sanctum leaf extract. Int J Chem Stud. 2013; 1(3): 1-4.

17. Saranyaadevi K, Subha V, Ernest Ravindran Rs, Renganathan S. Synthesis and caharacterization of copper nanoparticle using Capparis zeylanica leaf extract. Int J Chem Tech Res 2014; 6: 4533-41.

18. Naika HR, Lingaraju K, Manjunath K, Kumar D, Nagaraju G, Suresh D, Nagabhushana H. Green synthesis of $\mathrm{CuO}$ nanoparticles using Gloriosa superba L. extract and their antibacterial activity. J Taibah Uni Sci 2015; 9: 7-12. 
19. Angrasan J, Subbaiya R. Biosynthesis of copper nanoparticles by Vitis vinifera leaf aqueous extract and its antibacterial activity. Int J Curr Microbiol Appl Sci 2014; 3: 768-74.

20. Gopinath M, Subbaiya R, Selvam MM, Suresh D. Synthesis of copper nanoparticles from Nerium oleander leaf aqueous extract and its antibacterial activity. Int J Curr Microbiol Appl Sci 2014; 3 : 814-8.

21. Katha U, and Gajera H. Synthesis of copper nanoparticles by two different methods and size comparison. Int J Pharm Bio Sci 2014; 5: 533-40.

22. Subhankari I, Nayak P. Synthesis of copper nanoparticles using Syzygium aromaticum (Cloves) aqueous extract by using green chemistry. World J Nano Sci Technol 2013; 2: 14-7.

23. Shende S, Ingle AP, Gade A, Rai M. Green synthesis of copper nanoparticles by Citrus medica Linn.(Idilimbu) juice and its antimicrobial activity. World J Microbiol Biotechnol 2015; 31 : 865-73.

24. Kheirandish F, Delfan B, Mahmoudvand H, Moradi N, Ezatpour B, Ebrahimzadeh F, Rashidipour M. Antileishmanial, antioxidant, and cytotoxic activities of Quercus infectoria Olivier extract. Biomed Pharmacother 2016; 82: 208-15.

25. Saedi Dezaki E, Mahmoudvand H, Sharififar F, Fallahi S, Monzote L, Ezatkhah F. Chemical composition along with anti-leishmanial and cytotoxic activity of Zataria multiflora. Pharm Biol 2016; 54:752-8.

26. Abboud Y, Saffaj T, Chagraoui A, Brouzi K, Tanane O, Ihssane B. Biosynthesis, characterization and antimicrobial activity of copper oxide nanoparticles (CPNPs) produced using brown alga extract (Bifurcaria bifurcata). Appl Nanosci 2014; 4: 5716.

27. Das S, Das J, Samadder A, Bhattacharyya SS, Das D, KhudaBukhsh AR. Biosynthesized silver nanoparticles by ethanolic extracts of Phytolacca decandra, Gelsemium sempervirens, Hydrastis canadesis and Thuja occidentalis induce differential cytotaxicity through G2/M arrest in A375 cells. Colloids Surf B Biointerfaces 2013;101: 325-36.

28. Khatami M, Pourseyedi S. Phoenix dactylifera (date palm) pit aqueous extract mediated novel route for synthesis highstable silver nanoparticles with high antifungal and antibacterial activity. IET Nanobiotechnol 2015; 9:184-90.

29. Khatami M, Amini E, Amini A, Mortazavi SM, Kishani Farahani Z, Heli H. Biosynthesis of silver nanoparticles using pine pollen and evaluation of the antifungal efficiency. Iran J Biotechnol 2017; 15: 1-7.

30. Khatami M, Mehnipor R, Poor MHS, Jouzani GS. Facile biosynthesis of silver nanoparticles using Descurainia sophia and evaluation of their antibacterial and antifungal properties. J Clust Sci 2016; 27: 1601-12.

31. Soltani Nejad M, Khatami M, Shahidi Bonjar GH. Extracellular synthesis gold nanotriangles using biomass of Streptomyces microflavus. IET Nanobiotechnol 2016; 10: 33-8.

32. Li Z, Lee D, Sheng X, Chohen RF, Ruber MF. Two -level antibacterial coating with both release-killing and contactkilling capabilities. Langmuir 2006; 22: 9820-3.

33. Engelkirk J, Engelkirk P. Laboratory Diagnosis of Infectious, Duben Lippincott Williams \& Wilkins, 2008, pp. 168 